Gilvan Charles Cerqueira de Araújo' Silas Nogueira de Melo ${ }^{2}$

Data de submissão: 21-07-2013

Data de aprovação: 06-05-2014

1 Doutorando em Geografia pela Universidade Estadual Paulista - UNESP de Rio Claro. Email: gcca99@gmail.com

2 Doutorando em Geografia pela Universidade Estadual de Campinas - Unicamp. Email: silas. melo@yahoo.com.br

\section{Capitalismo estético e hiperconsumismo: contradições entre a pós-modernidade e o discurso ambiental}

\section{Capitalism aesthetic and hyper-consumption: contradictions between post-modernity and the environmental discourse}

\section{Resumo}

O artigo de cunho teórico discute a pós-modernidade, o discurso ambientalista e o capitalismo estético, tendo como ponto de partida e encontro o cenário contemporâneo do hiperconsumismo. Dessa forma, serão analisados alguns dos aspectos que caracterizam essa realidade social, política e econômica, a qual a sociedade atual está inserida. E, num âmbito de maior complemento e conclusão, será trazido para o debate o cruzamento do hiperconsumo com a frente ambientalista, considerando seus pontos de convergência e divergência.

Palavras-chave: Capitalismo estético. Discurso ambientalista. Pós-modernidade. Hiper-consumo.

\begin{abstract}
This article has a theoretical aspect, about the post-modernity, environmental discourse and the aesthetic capitalism, as initial point the actual setting of the hyper-consumerism. Therefore, will be examined some of the aspects who characterize this social, political and economic of this society and your present social reality. And, in the context of addition and discussion and conclusion, will be brought the intersection of hyper-consumerism and the environmental front, considering their point of convergence and divergence.
\end{abstract} Keywords: Capitalism Aesthetic. Environmentalist Discourse. Post-modernity. Hyper-consumption. 


\section{Introdução}

O mundo contemporâneo nos apresenta uma complexidade de aspectos, relações e especificidades imensurável. Temas que vão desde a problemática ambiental, perpassando pela volatilidade do modo de produção capitalista em sua modalidade financeira, o surgimento de novas sociabilidades nacionais, os limites da técnica e racionalidade ultrapassando fronteiras e previsões, os meandros ainda a serem compreendidos do processo de globalização, etc.

Essa quantidade de elementos complementares e divergentes fez surgir, nos últimos anos, uma terminologia que busca contemplar tal cenário, e, nesse caso a referência é a pós-modernidade. Autores como David Harvey (1996), Boaventura de Sousa Santos (2005) e Zygmunt Bauman (2001) dentre outros, trazem à discussão tanto a amplitude como a pertinência e operacionalidade de tal nomenclatura difundida em grande escala, principalmente nas ciências sociais. E essa preocupação se deve justamente ao labor empreendido na cunhagem de uma nova proposta de compreensão da atualidade, ao mesmo tempo em que se apresentam novas nuanças que se somam a esse contexto já em grande magnitude interpretativa.

O presente trabalho tem por objetivo traçar uma linha de discussão e de propostas passíveis de correlação entre este arco conceitual e concreto da pós-modernidade com uma das suas modalidades de interpretação e comportamento, ou seja, a existência e pujança de uma sociedade do hiperconsumo. E como ponto derradeiro da problemática posta e proposta serão apresentados alguns dos pontos de encontro entre a pós-modernidade, a sociedade do hiperconsumo e o discurso ambientalista, o que gera inevitavelmente frestas de perscrutação prática e teórica de irrevogável e essencial valoração não apenas para o meio acadêmico, mas para a sociedade como um todo.

\section{Pós-modernidade e o capitalismo estético}

As propostas de nomenclaturas sobre como a atualidade deve ser designada recebeu, em alguns centros, e de alguns representantes do meio acadêmico o nome de pós-modernismo ou era pós-moderna. Essa máxima conceitual e interpretativa objetiva em seu âmago abarcar, de um modo geral, todas as características que juntas fazem com que as formulações sociais, econômicas, culturais, étnicas e científicas das grandes narrativas intelectualistas da modernidade sejam consideradas esgotadas diante de uma nova compreensão mais dinâmica, abrangente, complexa e extremamente diversificada da humanidade no século XXI.

Tendo como base teórica a pós-modernidade como um todo, faz-se necessária uma delimitação dos campos científicos de análise da era pós-moderna, justamente pelo fato de essa última possuir várias facetas de manifestação e representação que, inerentemente, precisam ser estudados de uma forma mais profunda pelos diversos ramos da ciência.

Nossa delimitação de análise será o próprio modo de produção capitalista. E, dentro desse recorte, o capitalismo ocidental possui uma história de constantes transformações ao longo da trajetória da humanidade nestes últimos séculos. Dessa maneira, antes de se fazer uma argumentação sobre o capitalismo pós-fordista, é imprescindível a presença de uma breve reflexão sobre a decadência do capitalismo moderno ou clássico, calcado na produção em série, alienação dos trabalhadores e padronização do sistema produtivo e de consumo.

Com o intuito de termos em mãos uma referência temporal nos labirintos da história, façamos uma convenção de início da modernidade por volta da primeira grande revolução científica do ocidente, em meados do século XV (SANTOS, 2005). Esse período chamado de modernidade se arrastara também pelos séculos das luzes, XVII e XVIII, em que começaram a aparecer as primeiras fábricas na Inglaterra, e cujas principais características eram o trabalho em série e a padronização dos produtos fabricados.

Esse modelo de produção é o que chamamos de capitalismo clássico, aquele ampla e exaustivamente trabalhado por Marx em sua obra magna, salientando principalmente a indiferença perante o principal vetor da produção: a força de trabalho (a vida útil dos trabalhadores era reduzida devido às condições de trabalho nas indústrias), que em sua abundância e exploração era o que garantia a força e manutenção desse modo de produção.

Em contrapartida ao atual hiperconsumo tínhamos, no capitalismo industrial clássico, uma hiperprodução, por isso é que na própria descrição da ampliação do alcance do capitalismo, Karl Marx (1985) cita a exploração de novos mercados consumidores como coluna vertebral da produção europeia, pois naquela época a produção aumentava seguindo de perto o desbravamento das fronteiras de exploração do consumo, basta resgatar 
o pseudoesforço britânico em garantir a liberdade dos escravos pelo mundo.

O ponto máximo de sustentação dessa concepção do capitalismo será após a segunda revolução industrial - do petróleo e da eletricidade - entre as décadas de 1930 e 1940, principalmente após a quebra da bolsa de Nova Iorque em 1929 (a crise da produção) com finalização do processo na década de 1950, pois a segunda grande guerra ainda sustentaria o reerguimento de muitos ramos da indústria pesada e de bens de consumo não duráveis. Em meio a esse período, houve a fase de regulação do capital, compreendida no período que foi do final das II Guerra Mundial até meados dos anos 80, com o advento do Consenso de Washington (HARVEY, 1996). Com a entrada dessa nova fase, duas novas facetas do modo de produção capitalista se coincidiram, a financeira e a estética a partir do final do século XX e início do século XXI.

Resumidamente, podemos colocar o capitalismo industrial clássico no âmbito do modernismo, enquanto o capitalismo estético (do qual a chancela financeira faz parte, após 1971 com a queda do Tratado de Breton Woods nos EUA, e fim da equiparação do dólar ao ouro, contemplando assim a fase especulativa do capitalismo) estaria alinhado ao pós-modernismo das últimas três décadas majoritariamente. No quadro abaixo, é possível observar outras diferenças entre os paradigmas modernistas e pós-modernistas, em que o capitalismo se modulou ao longo dos anos:

Tabela 1: as diferenças entre o Modernismo e Pós-modernismo

\begin{tabular}{ll}
\hline modernismo & pós-modernismo \\
\hline romantismo/simbolismo & parafisica/dadaismo \\
forma (conjuntiva, fechada) & antiforma (disjuntiva, aberta) \\
propósito & jogo \\
projeto & acaso \\
hierarquia & anarquia \\
dominio/logos & exaustão/silêncio \\
objeto de arte/obra acabada & processo/ performance/happening \\
distância & participação \\
criação/totalização/sintese & descrição/desconstrução/antitese \\
presença & ausência \\
centração & dispersão \\
gênero/fronteira & texto/intertexto \\
semântica & retórica \\
paradigma & sintagma \\
hipotaxe & parataxe \\
metáfora & metonimia \\
seleção & combinação \\
raiz/profundidade & rizoma/superficie \\
interpretação/leitura & contra a interpretação/desleitura \\
significado & significante \\
lisible (legivel) & scriptible (escrevivel) \\
narrativa/grande histoire & antinarrativa/petite histoire \\
código mestre & idioleto \\
sintoma & desejo \\
tipo & mutante \\
genital/fálico & polimorfo/andrógino \\
paranóia & esquizofrenia \\
origem/causa & diferença-diferença/vestigio \\
Deus Pai & Espirito Santo \\
metafisica & ironia \\
determinação & indeterminação \\
transcendência & imanência \\
\hline Fonte: Hassan apud Harvey (1996, p. 48) & \\
& \\
\hline
\end{tabular}

O quadro de Hassan, trabalhado por Harvey (1996), em sua obra Condição Pós-moderna, é uma das mais ricas sínteses das alterações, discrepâncias e descontinuidades entre as fases do que o autor chama de modernismo para o pós-modernismo. Harvey irá transferir estas inflexões para o seu estudo particular, ou seja, a maneira como tais mudanças se comportaram no interior do modo capitalista de produção, o que o autor irá chamar de pós-fordismo - que é uma das formas de se denominar a fase atual do capitalismo -, no qual se inserem novas formas de se produzir, organizações de trabalho e objetivos comerciais:

Ela se apoia na flexibilidade dos processos de trabalho, dos mercados de trabalho, dos produtos e padrões de consumo. Caracteriza-se pelo surgimento de setores de produção inteiramente novos, novas maneiras de fornecimento de serviços financeiros, novos mercados e, sobretudo, taxas altamente intensificadas de inovação comercial, tecnológica e organizacional. A acumulação flexível envolve rápidas mudanças dos padrões do desenvolvimento desigual, tanto entre setores como entre regiões geográficas, criando, por exemplo, um vasto movimento no emprego no chamado 'setor de serviços', bem como conjuntos industriais completamente novos em regiões até então subdesenvolvidas [...]. Esses poderes aumentados de flexibilidade e mobilidade permitem que os empregadores exerçam pressões mais fortes de controle de trabalho sobre uma força de trabalho de qualquer maneira enfraquecida por dois surtos selvagens de deflação, força que viu o desemprego aumentar nos países capitalistas avançados (salvo, talvez, no Japão) para níveis sem precedentes no pós-guerra. O trabalho organizado foi solapado pela reconstrução de focos de acumulação flexível em regiões que careciam de tradições industriais anteriores e pela reimportação para os centros mais antigos das normas e práticas regressivas estabelecidas nessas novas áreas. A acumulação flexível parece implicar níveis relativamente altos de desemprego 'estrutural' (em oposição a 'friccional'), rápida destruição e reconstrução de habilidades, ganhos modestos (quando há) de salários reais e o retrocesso do poder sindical - uma das colunas políticas do regime fordista. (HARVEY, 1996, p. 140).

No bojo dessas mudanças do modo capitalista de produção emerge o denominado capitalismo estético - principalmente na vertente de preocupação e desenvoltura de novas formas de comercialização e consumo dos objetos e serviços, produzidos ou oferecidos por essa nova fase do capitalismo - o qual e no qual a palavra de ordem é a mobilidade do que é produzido de acordo com as especificidades de desejos e vontades do consumidor 


\section{(LIPOVETSKY, 2007).}

Dessa forma, tem-se a evolução do exclusivismo produtivo, que vai na direção contrária à unidimensionalização clássica do capitalismo mencionada por Marcuse (1967), mas, de sobremaneira estabelece toda uma nova dinâmica de comportamento dessas novas bases de produção, circulação e consumo no mundo atual:

\begin{abstract}
A meia vida de um produto fordista típico, por exemplo, era de cinco a sete anos, mas a acumulação flexível diminuiu isso em mais da metade em certos setores (como o têxtil e o de estuário), enquanto em outros - tais como as chamadas indústrias de 'thoughtware' (por exemplo videogames e programas de computador) - a meia vida está caindo para menos de dezoito anos (HARVEY, 1996, p. 148).
\end{abstract}

O teórico Zygmunt Bauman (2001) irá dissertar sobre essas novas nuanças do mundo atual, não apenas no âmbito do capitalismo pós-fordista, mas principalmente por influência desse último. Para o autor, a pós-modernidade seria uma época de liquidez de todas as relações, sejam elas econômicas, sociais, culturais ou políticas. E dentro dessa configuração do capitalismo flexível, pós-fordista, estético ou pós-moderno, um dos focos do autor será o avanço da dependência das pessoas com relação ao consumo imediato e desenfreado, e assim:

Nas novas circunstâncias, o mais provável é que a maior parte da vida humana e a maioria das vidas humanas consumam-se na agonia quanto à escolha de objetivos, e não na procura dos meios para os fins, que não exigem tanta reflexão (BAUMAN, 2001, p. 73).

E seguindo estas colocações, numa escala maior do capitalismo pós-fordista (e a depender do autor, contexto ou corrente de pensamento, também pós-modernista, estético, financeiro, líquido, etc) é possível buscar as principais características dessa fase do modo de produção capitalista:

- O importante não é a produção em si apenas, mas sim o produto em questão, essa é uma das molas propulsoras do capitalismo estético, não se parte do geral da produção para o particular da utilização pelo consumidor, mas sim, o contrário, primeiro é dado o passo da(s) especificidade(s) do consumidor para a posterior confecção do produto. Ex: indústria de cosméticos e eletrônicos;

- Atualmente os investimentos em publicidade e propaganda excedem em muito o que era gasto com essa ação em épocas passadas. Nesse ponto, temos talvez a pedra de toque de sustentação do capitalismo estético: de um lado o espetáculo social contribui para a difusão das mercadorias e por outro lado são as mercadorias que mantêm a estrutura de manutenção do espetáculo social. Por exemplo: os mega-acordos entre a mídia e as indústrias em geral. Há assim uma dupla evolução do capitalismo contemporâneo:

a) Passamos do capitalismo sólido da produção real e equivalente para a temível bolha do capitalismo especulativo do mercado financeiro. Essa mudança radical pode ter como ponto simbólico de passagem a anulação do tratado de Breton Woods, quando temos a total desvinculação da riqueza anunciada com a existente. Na prática o que ocorre daí por diante é a explosão do discurso financeiro sem limites do neoliberalismo, sem lei e sem rei $^{3}$, cujos resultados estamos assistindo nos últimos dois anos de recessão mundial devido ao crescimento descontrolado da especulação financeira;

b) Imaginemos duas representações simbólicas e ilustrativas do capitalismo industrial e estético, primeiro temos o clássico filme de Charles Chaplin, Tempos Modernos $^{4}$, em que verificamos com primazia as bases da produção em massa e do fordismo. No que tange ao capitalismo estético, podemos fazer uso do filme $A$ fantástica Fábrica de Chocolate de Roald Dahl de 1971 (essa comparação pode ser estendida também para o cenário de diferenciação do que era produzido e do consumo entre a Alemanha Oriental e Ocidental durante o período da guerra fria). Nesse segundo filme, vemos perfeitamente uma paródia com a busca incessante pela perfeição de representação da produção para o consumo de acordo com a vontade e não pela necessidade do consumidor.

Esses são alguns dos principais aspectos a serem levantados sobre as teorias do pós-modernismo, nas ciências sociais, majoritariamente, e a partir desse ponto central emergem as discussões como o capitalismo pós-fordista, a esteticidade produtiva adotada pelas empresas e marcas atualmente, e de que maneira essas duas vertentes convergem em uma nova lógica de produção vigente na atualidade.

\section{A sociedade do hiperconsumo}

3 Apesar de não ter um rei, o capitalismo financeiro possui seus profetas, que nada mais são que os países que compõem o circulo das nações controladoras do movimento cambial monetário e acionário: Estados Unidos da América, Reino Unido, Japão, Alemanha, etc.

4 O filme foi lançado em 1936 e mostra uma sutil crítica ao modelo de produção fordista e à exploração da mão de obra nas fábricas que emergiam na época. 
Quando falamos de consumismo, entendido como fluxo de circulação de mercadorias, devemos retomar ao nascimento do capitalismo contemporâneo, esse retrocesso histórico nos levará diretamente para o período de ascensão da terceira revolução industrial, ou seja, por volta de 1940 ou 1950, e devemos nos perguntar por que este período e não outro anterior ou posterior. Autores como David Harvey (1996), Gilles Lipovetsky (2007) e Bauman (2001) têm trabalhado com essa nova dinâmica da produção, circulação e consumo das mercadorias no bojo do modo produção capitalista:

A dinâmica de individualização dos produtos só pôde efetuar-se graças à alta tecnologia baseada na microeletrônica e na informática. As novas tecnologias industriais permitiram o desenvolvimento de uma "produção personalizada de massa" que consiste em montar, de maneira individualizada, módulos pré-fabricados (LIPOVETSKY, 2007, p. 79).

Essa proposta do consumo dirigido se alastrou e se fortaleceu como em nenhum outro período da história recente. Dentre as possiblidades abertas pelo pós-fordismo, o qual está inserido no movimento maior do pós-modernismo, está o aumento do apelo estético como recurso de uma "liberdade de consumo" ou de hiperconsumo $^{5}$, cada vez maior, e deste passo para o discurso do bem-estar por via do consumo foi uma questão de contingência e alinhamento de condições favoráveis para esta investida do modo de produção capitalista. Em outras palavras, temos que:

De um lado, este se afirma como um 'consumator', informado e 'livre', que vê seu leque de escolhas ampliar-se, que consulta portais e compradores de custo, aproveita pechinchas do low-cost, age procurando otimizar a relação qualidade/preço. Do outro, os modos de vida, os prazeres e os gostos mostram-se cada vez mais sobre a dependência do sistema mercantil. Quanto mais o hiperconsumidor detém um poder que lhe era desconhecido até então, mais o mercado estende sua tentacular; quanto mais o comprador está em situação de autoadministração, mais existe extrodeterminação ligada à ordem comercial" (LIPOVETSKY, 2007, p. 15).

As discussões concernentes a esse novo período

5 Na esfera da abundância das opções das mercadorias, o hiperconsumo se estabelece via "efeito manado" em que os desejos de propensão a consumir ficam impregnados no que se pode estabelecer de "inconsciente social" por meio das grandes e milionárias campanhas de marketing nos mais diferentes segmentos de público e faixas etárias dentro de uma sociedade. (MENEZES, 2008, p. 6). estético de consumo encontrarão seu auge nas obras de Hannah Arendt (1999) sobre a análise da exploração humana e do trabalho de enclausurar a subjetividade ao socialmente difundido e publicamente consumido. Sinteticamente temos uma nova configuração da compreensão do capitalismo, que, de uma forma geral, se insere no campo de mais um pilar moderno em decadência de suas bases narrativas, ou seja, a liberdade de produção e consumo se transforma em uma verdadeira prisão da estética, ou como demonstra Debord (1997) a difusão do parecer em detrimento do ter e do ser ${ }^{6}$. Em outras palavras temos que:

$\mathrm{O}$ aspecto estético da mercadoria no sentido mais amplo - manifestação sensível e sentido de seu valor de uso - separa-se aqui do objeto. A aparência torna-se importante — sem dúvida importantíssima - na consumação do ato da compra, enquanto ser. O que é apenas algo, mas não parece um 'ser', não é vendável. O que parece ser algo é vendável. A aparência estética, o valor de uso prometido pela mercadoria, surge também como função de venda autônoma no sistema de compra e venda. No sentido econômico está-se próximo de, e será finalmente obrigatório, em razão da concorrência, ater-se ao domínio técnico e à produção independente desse aspecto estético. O valor de uso estético prometido pela mercadoria torna-se então instrumento para se obter dinheiro. Desse modo, o seu interesse contrário estimula, na perspectiva do valor de troca, o empenho em se tornar uma aparência de valor de uso, que exatamente por isso assume formas bastante exageradas, uma vez que, da perspectiva do valor de troca, o valor de uso não é essencial. Nesse contexto, o aspecto sensível torna-se portador de uma função econômica: o sujeito e o objeto da fascinação economicamente funcional. Quem domina a manifestação, domina as pessoas fascinadas mediante os sentidos (HAUG, 1997, p. 27).

Conforme expressado por Haug (1997), existe de fato a exploração pelo fascínio do consumo, e nesse ponto é que se conjugam duplamente o consumismo com o espetacular, num contínuo movimento de complementariedade, no qual o consumidor surge como principal foco e objetivo. Por essa razão, Bauman (2001) defende que, nesse panorama do capitalismo estético (e espetacular), há uma pujante "presença da ausência", em outros termos, há o aproveitamento do efêmero e da falta de referenciais de

6 A título de aprofundamento dessa questão, podemos citar a peculiar e inigualável obra de Jean Baudrillard: Simulacros e Simulação. Trad. Maria João da Costa Pereira. Lisboa: Relógio d' Água, 1991. 
significância da vida para que o produto, ou ao menos os diferentes tipos de consumo deste, supre tal condição, pois na oferta do múltiplo e rápido esquece-se do único e permanente, a satisfação dá lugar ao sentimento de falta e inocuidade: "[...] a infelicidade dos consumidores deriva do excesso e não da falta de escolha”. (BAUMAN, 2001, p. 75).

O espetáculo, em outras palavras, a sociedade do espetáculo como diria Debord (1997) e o hiperconsumo calcado no esteticismo estão assim intimamente ligados. A infelicidade é superada pela proposta do consumo exacerbado, na forma de uma catarse sentimental, efêmera é claro, mas suficiente para fazer com que o breve momento de satisfação da aquisição de um produto seja transformado em uma apresentação do estágio máximo de sublimidade, esta última não necessariamente do ser (alguém, ou alguma coisa), mas do ter, ou seja, o produto adquirido naquele momento dentro de determinados padrões contextuais, tanto espetaculares como consumistas:

O hiperconsumo é um espetáculo do conforto. Aos que possuem poder aquisitivo pode consumir segurança e luxo descartáveis em ruas que são verdadeiros "bunkers de paz" em meio à dispersão da violência. $\mathrm{O}$ templo da felicidade do hiperconsumo de massa, o shopping center é o retrato da negação da cidade e dá a sensação de segurança e felicidade das compras com tranquilidade. $\mathrm{O}$ consumo não é apenas uma amálgama entre necessidade e disponibilidade, mas comprar evasivamente se tornou um ato de prazer com características sexuais (em referência ao gozo freudiano). A felicidade diante de uma compra abstrata e utilidade pífia realçam as características de ansiedade do hiperconsumidor. O desejo de comprar cada vez mais torna o consumo como um ato de felicidade propriamente dita. O marketing de massa sabe exatamente destas características dos consumidores e exploram a exaustão o viés da angústia e o desejo pelo fetiche da mercadoria através da pasteurização e homogeneização das necessidades humanas: "Você precisa experimentar o produto "A", porque "A" vai fazer sua vida mais feliz!". A "felicidade instantânea" se configura em um autômato saciar da necessidade passageira e, por sua vez, a publicidade capta tão eloquentemente suas matrizes do adornamento da mercadoria como objeto simbólico constituinte de uma miríade de desejos consumistas. Assim que o desejo da aquisição for concretizado via cartão de crédito ou débito automático, uma nova carência surgirá e renovará todo o processo de angustia pela saciedade do consumo. (MENEZES, 2008, p. 10).

A felicidade do hiperconsumo está associada ao caminhar da propaganda, marketing, exposição e exploração das marcas. $\mathrm{O}$ argumento apresentado por Mene- zes (2008) se repete em autores como Lipovetsky (2007) e Debord (1997), e também de Santos (1987) quando este afirma que há uma busca pelo "consumidor mais que perfeito" - e seu estudo se volta ao caso brasileiro especificamente. O estético e seu apelo de possiblidade de construir um mundo de consumo com as características individuais de cada um é o presente e, por enquanto, a vanguarda do modo de produção capitalista para o século XXI, passível ainda de aprofundamentos da sua magnitude, força e poder de impacto nas relações sociais contemporâneas.

\section{A contradição inevitável: o discurso ambien- talista}

Até este momento, foram apresentadas algumas das características do pós-modernismo e pós-fordismo em sentido amplo, e do capitalismo estético em sentido restrito. Mas, no cerne das discussões envolvendo a estética, a produtividade e o hiperconsumo, há uma vertente de grande exploração atualmente, trata-se do discurso "verde" ou ambientalista, o qual, por meio de uma eficiente modulação prática e discursiva, vem tomando frente nos mais recentes projetos e propostas do modo capitalista de produção.

Para melhor entendermos os aspectos do ambientalismo contemporâneo, é possível fazer uso das colocações de Frederico Loureiro (2003) que nos apresenta uma rica síntese das diferentes modulações retóricas do discurso ambientalista na contemporaneidade. Dessa forma temos desde o ambientalismo do terceiro setor (organizações não governamentais) até os ambientalismos religioso e estatal. No quadro abaixo se observam as principais diferenciações dessas correntes do movimento ambientalista:

Quadro 1: Os tipos de ambientalismos por Frederico Loureiro

Ambientalismo stricto sensu - organizações sociais e grupos comunitários ambientalistas de três tipos (profissionais, semiprofissionais e amadores).

Ambientalismo governamental - agências estatais de meio ambiente, nos níveis federal, estadual ou municipal.

Socioambientalismo - organizações não governamentais, sindicatos e movimentos sociais que têm objetivos sociais precípuos, mas incorporam a dimensão ambiental em sua atuação e discurso.

Ambientalismo científico - pessoas, grupos e instituições, que desenvolvem pesquisas científicas sobre a questão ambiental.

Ambientalismo empresarial - empresários que vinculam sua produção a certos critérios da sustentabilidade ambiental, destacadamente ao conceito de Qualidade Total e às normas ISO. 
Ambientalismo político-profissional - quadros partidários procuram estabelecer políticas específicas que vinculem a dimensão ambiental às políticas públicas.

Ambientalismo religioso - representantes de religiões e tradições espirituais, que relacionam a dimensão ambiental à consciência do divino e do sagrado.

Ambientalismo de educadores, profissionais de comunicação e arte - indivíduos, organizados coletivamente ou não, preocupados com 0 ambiente, que possuem grande capacidade de influir na consciência das massas.

Fonte: Loureiro, 2003, p. 2.

Essas vertentes do ambientalismo apresentadas por Loureiro (2003) evidenciam o dado explícito da contemporaneidade, ou seja, a força que o discurso de preocupação com os aspectos naturais de nosso mundo encontra-se em diferentes meios e públicos. Os grupos empresariais (e a chancela ISO 14.000 de responsabilidade ambiental, buscada pelas empresas é um bom exemplo disso) e a inserção desse paradigma nos currículos escolas faz com que seja praticamente impossível compreender o mundo atual sem relevar as características do discurso ambiental. A presença de tantas modalidades de adaptação do ambientalismo mostrar-se-á passível de constatação no proporcional crescimento dessa pauta na sociedade, nos governos, empresários e demais setores da sociedade no Brasil e no mundo.

Hoje o que se observa é uma absorção do ambientalismo prático e discursivo pela lógica da produção e do consumo contemporâneos. Conforme apresentado anteriormente, em autores como Harvey (1996) e Bauman (2001), a mudança nos padrões de comportamento, e consequentemente do consumo, da sociedade faz com que surjam novas maneiras de se vivenciar essa realidade. No Brasil, em pesquisa realizada em 2012 pela União, o meio ambiente aparece como principal motivo de orgulho e o $6^{\circ}$ em preocupação geral da população.

Figura 1: Principais motivos de orgulho dos brasileiros

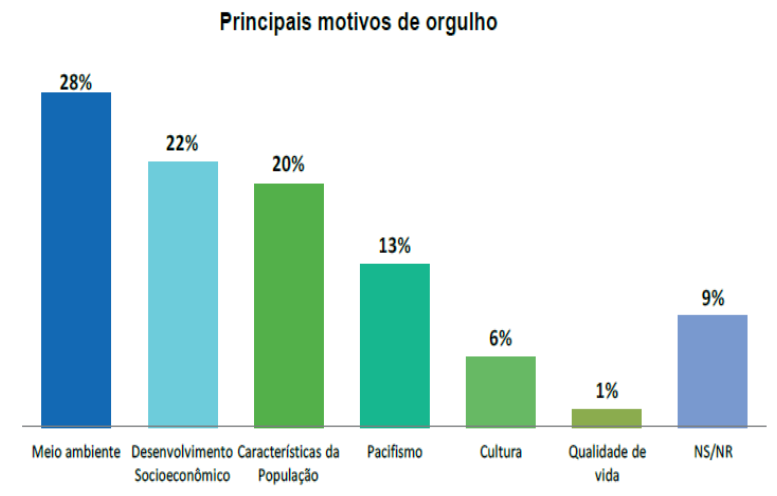

Fonte: (BRASIL, 2012, p. 14).
Figura 2: Pessoas que disseram não haver problema ambiental no Brasil ou não souberam opinar

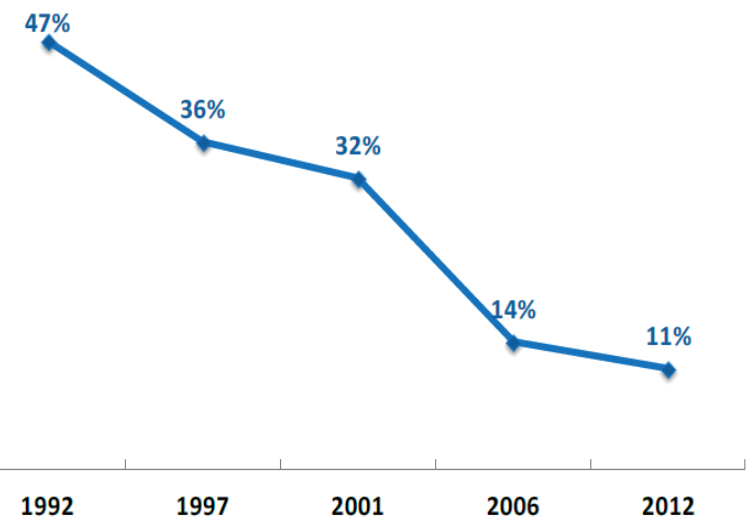

Fonte: (BRASIL, 2012, p. 22)

Figura 3: Principais problemas ambientais do mundo

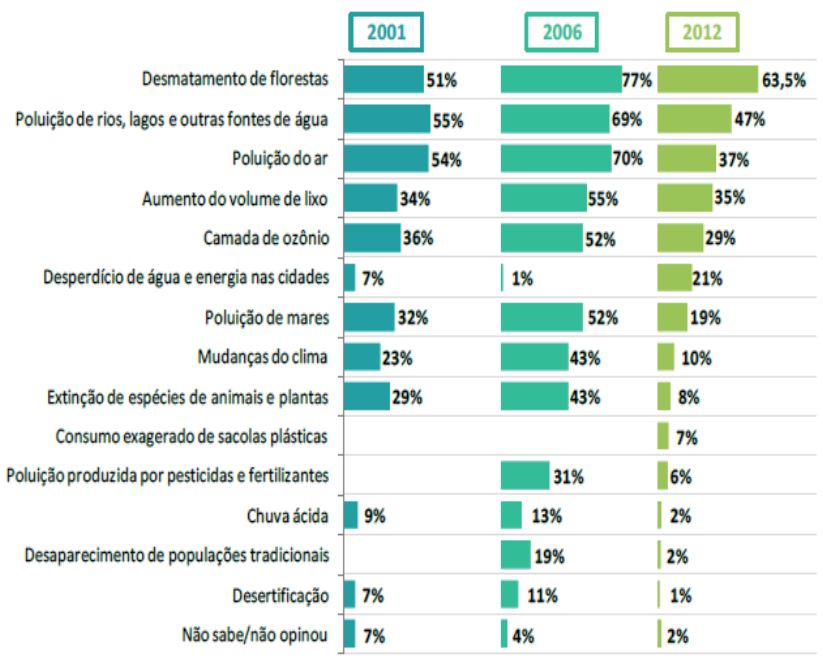

Fonte: (BRASIL, 2012, p. 20).

Os dados apresentados anteriormente são elucidativos no que diz respeito ao crescimento da problemática ambiental à sociedade. No caso específico brasileiro, o crescimento foi incisivo, e quando se é feito um exercício de ampliação escalar de tal cenário chega-se no âmbito das grandes conferências internacionais, os acordos diplomáticos para o desenvolvimento sustentável e demais facetas do discurso ecológico e ambientalista na atualidade, ou seja, a escala de chegada e ação do ambientalismo vai das quadras de um bairro aos programas mundiais de medidas contra os impactos ambientais, provocados em sua grande maioria por ação antrópica.

O Ministério do Meio Ambiente havia feito uma pesquisa similar no ano de 1997, a qual tratava sobre a visão da sociedade em relação aos problemas ambientais no Brasil e no mundo, e essa nova edição de 2012 nos 
traz uma proficuidade imensurável de informações para interpretação e debate:

Ao observar algumas destas opiniões testadas nas demais edições da pesquisa, fica nítido que, desde 1997 até os dias atuais, a concepção pró-preservação e uso consciente dos recursos naturais vêm se fortalecendo e crescendo entre os brasileiros. Dentre as opiniões analisadas nas várias edições, a que apresenta maior variação nestes 15 anos é a concordância sobre a insustentabilidade da forma como a água vem sendo utilizada, configurando um crescimento de 27 pontos percentuais. Em 1997, 55\% dos respondentes brasileiros concordavam com a afirmação "Da forma como usamos a água, dentro de pouco empo não teremos água para beber". Atualmente, $82 \%$ da população concorda com tal afirmação. (BRASIL, 2012, p. 31).

Neste contexto, ganha força, nos dias atuais, o consumo verde (a produção e a circulação também se inserem em tal perspectiva), de uma maneira que este passa a não mais se comportar apenas como um ponto de crítica e questionamento da produção e consumo, mas também, passa a ser condicionado como aspecto valorativo de tudo o que é produzido. Essa é a essência primeira dos inúmeros selos ambientais presentes com maior frequência nos últimos anos em empresas, indústrias e demais meios de sustentação da lógica capitalista:

[...] busca pela qualidade com impactos ambientais mínimos; preferência por produtos e ações que demandem menos quantidade de recursos naturais e que sejam menos nocivos ao meio ambiente; opção por artigos recicláveis, biodegradáveis e reutilizáveis; prestígio a empresas responsáveis socialmente e comprometidas com o meio ambiente; recusa a consumir produtos, utilizar serviços e apoiar ações de depreciem espécies em extinção; proatividade em relação às certificações ambientais; disposição em reduzir conforto, ganho econômico e conveniência em benefício de um consumo sustentável. (GIACOMINI, 2004, p. 70).

O ponto estético de confluência entre o ambientalismo e as novas modulações do sistema capitalista de produção é justamente a adoção da chancela ambiental como recurso e meio de difusão das qualidades de aquisição, compra e consumo de determinados produtos, sejam duráveis ou não duráveis. E, em ambos os casos, tanto de produtos de longa ou curta durabilidade, o discurso ambientalista anexa-se, tanto como agregativo de valor como também de fortalecimento da defesa qualitativa desses produtos, sejam eles objetos ou serviços de diferentes tipos:

O consumismo nunca é absoluto; sempre ocorre em função de demandas individuais, culturais, coletivas e ambientais. Desse modo, não é fácil precisar se determinada ação de consumo registrou excesso ou foi além das necessidades. Embora parcialmente, pode-se externar um quadro consumista observando os danos ambientais. Portanto, a mensuração objetiva do consumismo será sempre indicativa ou sugestiva. (GIACOMINI, 2008, p. 65).

A citação abaixo, de Fátima Portilho (2005), apesar de longa, acaba por ser uma síntese completa dos argumentos apresentados até este momento. Isso significa dizer que o discurso ambiental alinhado com o hiperconsumo atual, e ambos fazendo uso tanto do apelo estético como da amplitude espetacular, acabam por voltar-se novamente para o indivíduo. $\mathrm{O}$ sujeito passa a receber $\mathrm{o}$ poder da escolha e, mais do que isso, num âmbito maior, é colocada em suas mãos (ao menos discursivamente) a responsabilidade dos rumos ambientais do próprio planeta, por meio da consciência no seu consumo ecologicamente correto. Mas a armadilha do discurso verde ocorre no momento em que justamente ele permanece, em essência, como uma estratégia discursiva de forte impacto social, quando na verdade se comporta como uma nova forma de adaptação do capitalismo frente aos desafios de sua permanência na sociedade atual:

O consumidor verde foi amplamente definido como aquele que, além da variável qualidade/ preço, inclui em seu "poder de escolha", a variável ambiental, preferindo produtos que não agridam ou sejam percebidos como não-agressivos ao meio ambiente. Dessa forma, o movimento de consumo verde enfatizou a habilidade dos consumidores agirem em conjunto, trocando uma marca X por uma marca $\mathrm{Y}$, ou mesmo parando de comprar um determinado produto, para que os produtores percebessem as mudanças na demanda. As ações e as escolhas individuais motivadas por preocupações ambientais passaram a ser vistas como essenciais, e o consumidor como o responsável, através de suas demandas e escolhas cotidianas, por mudanças nas matrizes energéticas e tecnológicas do sistema de produção. No entanto, essa estratégia de "comprar um futuro melhor" acabou sendo rapidamente posta em questão, virando uma grande armadilha. $\mathrm{O}$ consumo verde atacaria somente uma parte da equação, a tecnologia, e não os processos de produção e distribuição, além da cultura do consumo propriamente dita. A estratégia de consumo verde pode ser analisada, ainda, como uma espécie de transferência da atividade regulatória em dois aspectos: do Estado para o mercado, através de mecanismos de autorregulação; e do Estado e do mercado para o cidadão, através de suas escolhas de consumo. Assim, ambos - governos e empresas - 
encorajariam a responsabilidade individual, implícita ou explicitamente, através de referências ao poder do consumidor, ao "bom cidadão" ou à valorização da contribuição pessoal de cada um, transferindo a responsabilidade para um único lado da equação: o indivíduo. (PORTILHO, 2005, p. 3)

Os gráficos apresentados anteriormente, nos quais se observa um grande crescimento no interesse e preocupação da população com as questões ambientais, mostram tanto o avanço da economia e consumo verde, como também a força do espetáculo como forma de contribuição para o fortalecimento desse discurso, e, nesse sentido, inserem-se obras cinematográficas, campanhas publicitárias, inserção do ambientalismo nos currículos escolares, etc:

No momento em que se intensificam as ameaças de catástrofes ecológicas a temática do 'consumo durável' encontra amplo eco, aparecendo o hiperconsumidor como o ator a ser responsabilizado com toda urgência, uma vez que suas práticas excessivas desiquilibram a ecoesfera. (LIPOVETSKY, 2007, p. 13).

É importante destacar que a presença deste discurso - ou discursos como diria Loureiro (2003) possuem seu grau de importância frente à emergência de uma situação de inerente complexidade com o meio ambiente. $\mathrm{O}$ questionamento posto e trazido à tona é a maneira pela qual o fundo da questão ambiental acaba por se tonar um profícuo fosso de exploração pelo hiperconsumismo, associado ao espetacular e pela lógica estética do capitalismo contemporâneo.

O apoio público e privado na continuidade da força do discurso ambiental como parte indissociável das novas estratégias de mercado é uma realidade que não pode ser negada, havendo desse modo a necessidade de questioná-la para que assim possamos compreender melhor essa complexidade, não apenas do modo de produção capitalista contemporâneo, mas da própria sociedade como um todo.

\section{Conclusão}

Para concluirmos o texto, podemos fazer um exercício cotidiano de observação e análise da realidade que nos envolve. Veremos que o capitalismo estético é tão explícito quanto à trivialidade de nossos atos e que a inserção do discurso ambientalista em seu âmago é apenas uma questão de querer abarcar uma considerável parcela de sua estrutura de funcionamento, mais especificamente aquela destinada à divulgação dos caracteres qualitativos dos produtos.

Por isso este estudo buscou contribuir para a discussão sobre a pós-modernidade, o discurso ambientalista e o capitalismo estético. Temas relacionados à contemporaneidade, como é o caso do capitalismo estético e consequentemente o hiperconsumo e suas implicações são de suma importância de serem trabalhados nas ciências que tratam da relação do ser humano consigo mesmo e o meio, contemplando, assim, desde os aspectos técnico-informacionais, industriais e político-ambientais que as envolvem numa constate multiplicidade de relações.

\section{Referências}

ARENDT, H. A Condição humana. 9. ed. Rio de Janeiro: Forense Universitária, 1999.

BAUMAN, Z. Modernidade líquida. Rio de Janeiro: J. Zahar, 2001.

BAUDRILLARD, J. Simulacros e simulação. Lisboa: Relógio d'Água, 1991.

BRASIL. O que o brasileiro pensa do meio ambiente e consumo sustentável (Pesquisa de Opinião, Edição 2012). Brasília: Ministério do Meio Ambiente (MMA), 2012 .

DEBORD, G. A sociedade do espetáculo. Rio de Janeiro: Contraponto, 1997.

GIACOMINI FILHO, G. Ecopropaganda. São Paulo: SENAC, 2004.

GIACOMINI FILHO. Meio ambiente e consumismo. São Paulo: SENAC, 2008.

HARVEY, D. A condição pós-moderna. São Paulo: Edições Loyola, 1996.

HAUG, W. F. A crítica da estética da mercadoria. São Paulo: Unesp, 1997.

LIPOVETSKY, G. A felicidade paradoxal: ensaio sobre a sociedade de hiperconsumo. São Paulo: Companhia das Letras, 2007.

LOUREIRO, C. F. B. Movimento ambientalista e o pensamento crítico. Rio de Janeiro: Quartet, 2003.

MARCUSE, H. A ideologia da sociedade industrial. Rio de Janeiro: Zahar, 1967. 
MARX, K. O Capital: crítica da economia política. Livro Primeiro: o processo de produção do capital. 10. ed. São Paulo: Difel, 1985.

MENEZES, W. F. A ilusão da felicidade: autofagia, angústia e barbárie na sociedade de hiperconsumo. In: CONGRESSO PORTUGUÊS DE SOCIOLOGIA: Mundos Sociais: Saberes e Práticas, 6, 2008, Lisboa. Anais... 2008.

PORTILHO, F. Consumo sustentável: limites e possibilidades de ambientalização e politização das práticas de consumo. Cadernos EBAPE.BR (FGV), Rio de Janeiro, v. 3, p. 1-12, 2005.

SANTOS, B. S. A critica da razão indolente: contra o desperdício da experiência. São Paulo: Cortez 2005.

SANTOS, M. O Espaço do cidadão. São Paulo: Nobel, 1987. 